\title{
Optimization of edible coating composition to retard strawberry fruit senescence
}

\author{
Clara Ribeiro $^{\mathrm{a}, \mathrm{b}, *}$, António A. Vicente ${ }^{\mathrm{a}}$, José A. Teixeira ${ }^{\mathrm{a}}$, Cândida Miranda ${ }^{\mathrm{b}}$ \\ ${ }^{a}$ Centro de Engenharia Biológica, Universidade do Minho, Campus de Gualtar, 4710-057 Braga, Portugal \\ ${ }^{\mathrm{b}}$ Research and Development Department, Frulact, S.A., Rua do Outeiro, 589, Gemunde, 4475-150 Maia, Portugal
}

Received 26 June 2006; accepted 21 November 2006

\begin{abstract}
The ability of polysaccharide-based (starch, carrageenan and chitosan) coatings to extend the shelf-life of strawberry fruit (Fragaria ananassa) were studied, mainly for industrial applications. The coatings and strawberries were characterized in terms of their physical properties (superficial properties, wettability, oxygen permeability) in order to optimize coating composition. The optimized coatings were then applied to the fruit both in the laboratory and in the field and their effects on relevant quality parameters assessed. The superficial tension of the strawberry was $28.94 \mathrm{mN} / \mathrm{m}$, and its polar and dispersive components were 5.95 and $22.99 \mathrm{mN} / \mathrm{m}$, respectively. The critical superficial tension of the strawberry, obtained from a Zisman plot, was $18.84 \mathrm{mN} / \mathrm{m}$. For each polysaccharide-based coating the best wettability was obtained for compositions: $2 \%$ starch and $2 \%$ sorbitol; $0.3 \%$ carrageenan, $0.75 \%$ glycerol and $0.02 \%$ Tween $80 ; 1 \%$ chitosan and $0.1 \%$ Tween 80. The oxygen permeability of carrageenan films was approximately $40 \%$ of that obtained with starch films. The addition of calcium to the starch film-forming solution produced an increase in the film thickness; nevertheless no significant differences in oxygen permeability were obtained between films with and without calcium. The effects of application of these coatings to fresh strawberries were assessed by determining color change, firmness, weight loss, soluble solids and microbiological growth over 6 days. No significant colour differences were found, and the minimum firmness loss was obtained in strawberries coated with carrageenan and calcium chloride. The minimum loss of mass was obtained for fruit with chitosan and carrageenan coatings both with calcium chloride. The addition of $1 \%$ di-hydrated calcium chloride to the coatings reduced the microbial growth rate on the fruit. The minimum rate of microbial growth was obtained for strawberries coated with chitosan and calcium chloride. The industrial application of calcium-enriched carrageenan coating on fresh strawberries resulted in a decrease in firmness loss when compared to non-coated fruit.
\end{abstract}

(c) 2006 Elsevier B.V. All rights reserved.

Keywords: Edible coatings; Strawberry shelf-life; Oxygen permeability; Wettability of edible coatings

\section{Introduction}

Research on edible coatings and films has been intense in recent years. Attempts to diminish crop losses and maintain the quality of fresh fruit for a longer period is a priority for all the producers. This is true both for fruit being directly sold to the consumer and for further processing. The development of coatings from polysaccharides has brought an

\footnotetext{
* Corresponding author at: Centro de Engenharia Biológica, Universidade do Minho, Campus de Gualtar, 4710-057 Braga, Portugal.

Tel.: +351229287 910; fax: +351229287919.

E-mail address: clara.meira@ frulact.pt (C. Ribeiro).
}

increase in new types of coatings for extending the shelf-life of fruit and vegetables because of the selective permeabilities of these polymers to $\mathrm{O}_{2}$ and $\mathrm{CO}_{2}$. Polysaccharide based coatings can be used to modify the internal atmosphere of the fruit and thus retard senescence (Nisperos-Carriedo, 1994).

Even though some edible coatings have been successfully applied to fresh products, other applications adversely affect quality. Modification of the internal atmosphere by the use of edible coatings can increase disorders associated with high $\mathrm{CO}_{2}$ or low $\mathrm{O}_{2}$ concentrations (Ben-Yehoshua, 1969) Therefore it is only natural that the control of gas permeability of the films should be a priority in their development. 
The effectiveness of edible coatings for protection of fruit and vegetables depends primarily on controlling the wettability of the coating solutions, which affects the coating thickness of the film (Park, 1999). Edible coating formulations must wet and spread uniformly on the fruit's surface and, upon drying, a coating that has adequate adhesion, cohesion, and durability to function properly (Krochta and Mulder-Johnston, 1997) must be formed. Among other functionalities, edible coatings can act as carriers for food additives such as antioxidants and antimicrobial agents onto the surface of the food.

The aim of this work was to study the ability of starch, carrageenan and chitosan based coatings to extend the shelflife of strawberry fruit. This study was divided into two parts: in the first part coating composition was optimized and $\mathrm{O}_{2}$ permeability of coating solutions was determined; in the second, the coatings were applied to the strawberries, both in the laboratory and in the field, and the changes in the quality parameters were followed during storage of the coated fruit.

\section{Materials and methods}

\subsection{Materials}

All polysaccharides used in this study were food-grade. Specific materials included starch Crisp Coat 868 (National Starch, Germany), with approximately $30 \%$ amylose content, к-carrageenan DX5253 (FMC, Belgium), chitosan powder with $90 \%$ deacetylation (Aqua Premier Co., Thailand), sorbitol 97\%, polyethylene glycol MW 200 and Tween 80 (Acrōs Organics, Belgium), glycerol 87\% (Panreac, Spain), $\mathrm{NaOH}$ $99 \%$, citric acid and calcium chloride (Merck, Germany), $\mathrm{HCl}$ $37 \%$ (Riedel deHaën, Germany).

\subsection{Coating solutions}

Solutions with $2 \%$ (w/v) starch were gelatinized by heating at $90{ }^{\circ} \mathrm{C}$, the $\mathrm{pH}$ value was adjusted to 5.6 with $50 \%(\mathrm{w} / \mathrm{v})$ citric acid solution and the solutions were equilibrated for $10 \mathrm{~min}$. Sorbitol was added as a plasticizer at a concentration of $2.0 \mathrm{~g}_{\text {solute }} / \mathrm{L}_{\text {solution }}$.

Carrageenan solutions were prepared by dissolving $0.3 \%$ $(\mathrm{w} / \mathrm{v})$ carrageenan in distilled water, and heating at $80^{\circ} \mathrm{C}$ for $10 \mathrm{~min}$; the $\mathrm{pH}$ value was adjusted to 5.6 with $50 \%(\mathrm{w} / \mathrm{v})$ citric acid solution. Glycerol was used as a plasticizer, at a concentration of $0.75 \%(\mathrm{w} / \mathrm{v})$. Tween 80 was added to the solution as a surfactant with various concentrations (between 0.01 and $0.1 \%(\mathrm{w} / \mathrm{v}))$.

Chitosan solutions were prepared according to El Ghaouth et al. (1991). Chitosan solutions were made by dispersing $1 \mathrm{~g}$ of chitosan in $80 \mathrm{~mL}$ of distilled water to which $2.5 \mathrm{~mL}$ of $10 \mathrm{~N} \mathrm{HCl}$ was added to dissolve the chitosan. The $\mathrm{pH}$ value was adjusted to 5.6 with $1 \mathrm{~N} \mathrm{NaOH}$ and $0.1 \mathrm{~mL}$ of Tween 80 was added as a surfactant. The solution was made up to $100 \mathrm{~mL}$.

\subsection{Wettability}

Both contact angle $(\theta)$ and liquid-vapor surface tension $\left(\gamma_{\mathrm{LV}}\right)$ were determined with a face contact angle meter (OCA 20, Dataphysics, Germany). The surface tension of the coating solution was measured by the pendant drop method using the Laplace-Young approximation (Song and Springer, 1996). Samples of the coating solution where taken with a $500 \mu \mathrm{L}$ syringe (Hamilton, Switzerland) in order to determine the drop shape, using computer-aided image processing. The diameter of the needle $(0.72 \pm 0.01 \mathrm{~mm})$, necessary for $\gamma_{\mathrm{LV}}$ determination, was obtained with a digital micrometer (Mitutoyo, US). The contact angle at the strawberry surface was measured by the sessile drop method (Newman and Kwok, 1999), in which a droplet of the tested liquid was placed on a horizontal surface and observed with a face contact angle meter. To avoid changes on the strawberry surface, measurements were made in less than $60 \mathrm{~s}$.

Twenty replicates of both the contact angle at the strawberry surface and of the liquid-vapour surface tension measurements were performed at $(19 \pm 1){ }^{\circ} \mathrm{C}$.

Estimation of the critical surface tension $\left(\gamma_{\mathrm{C}}\right)$ of strawberry surface was obtained by extrapolation from the Zisman plot (Zisman, 1964). This plot has been obtained using water, formamide, bromonaphthalene and toluene.

\subsection{Oxygen permeability}

The method used in was based on that of the ASTM D3985-02 (2002). A film made from the same material as each of the coatings was sealed between two superimposed chambers, each one having two channels. In the lower chamber, a controlled stream of pure $\mathrm{O}_{2}$ flowed, thus maintaining constant the $\mathrm{O}_{2}$ pressure in this compartment $(\approx 1 \mathrm{~atm})$. In the upper compartment a $\mathrm{N}_{2}$ stream $(5-15 \mathrm{~mL} / \mathrm{min})$ acted as a carrier of the permeated $\mathrm{O}_{2}$. The entrance flows of the two chambers were linked to a pressure gauge to guarantee that there is no pressure gradient between the two chambers.

The $\mathrm{O}_{2}$ concentration at the upper chamber was determined using an $\mathrm{O}_{2}$ sensor at the outlet of that chamber, therefore allowing the calculation of the amount of $\mathrm{O}_{2}$ crossing the film. At the end of each assay the film was carefully removed for determination of its thickness. For this analysis ten measurements at distinct points on the film were made using a digital micrometer (Mitutoyo, USA).

\subsection{Physicochemical properties of coated fruit}

The laboratory assays were made with fresh strawberries (Fragaria ananassa cv. Camarosa) purchased at the local market; the fruit were randomly distributed in seven equal lots, weighing $5 \mathrm{~kg}$ each. One of the lots was taken as the control while the remaining six were used for the experiments with the three coatings, either in the absence or presence of calcium. Sprays of the different coating solutions were applied to the lots, which were then stored at 
controlled temperatures $\left(0-5{ }^{\circ} \mathrm{C}\right)$ with a relative humidity of $85-90 \%$.

Weight loss of fresh strawberries during storage was measured by daily monitoring the weight changes of 20 fruit, randomly chosen (with a total approximate mass of $200 \mathrm{~g}$ ) from each of the $5 \mathrm{~kg}$ lots.

For the analysis of color and soluble solids content, 20 randomly chosen fruit (with a total approximate mass of $200 \mathrm{~g}$ ) from each $5 \mathrm{~kg}$ lot were homogenized with a high speed mixer. Soluble solids were determined according to the AOAC 932.12 standard method; the analyses were performed with a refractometer (GPR 12-70, Index Instruments, UK). Three replicates were made for each measurement and the soluble solids content was expressed in \% of soluble solids. The color of the fruit was determined with a Minolta colorimeter (CR 300; Minolta, Japan), recording CIE $L^{*} a^{*} b$ values, being $L^{*}$ (lightness), $a^{*}$ (redness) and $b^{*}$ (yellowness). The color measurements were performed as follows: three portions of $25 \mathrm{~g}$ were taken from every sample of homogenized fruit (each of those samples representing each of the $5 \mathrm{~kg}$ lots) and were placed on three black dishes with $5.5 \mathrm{~cm}$ of diameter. On each dish (i.e., on every replicate) the color was measured in five different points: in the centre, and in the vertices of an imaginary square of $5.5 \mathrm{~cm}$, centered in the centre of the dish. These five values were averaged and the three averages thus obtained for each sample were averaged again, the color being expressed as lightness $\left(L^{*}\right)$ and chroma $\left(\left(a^{2}+b^{2}\right)^{1 / 2}\right)$.

For the laboratory assays, firmness was determined using a Texture Analyzer (TA-XT2, Stable Micro Systems, UK). An Ottawa cell with a holed extrusion plate $(\phi=6.5 \mathrm{~mm})$ was used with a compression load cell of $25 \mathrm{~kg}$. Each experiment was conducted with $50 \mathrm{~g}$ of strawberries (approximately five strawberries) at a compression speed of $1.5 \mathrm{~mm} / \mathrm{s}$. Four replicates were used for each determination. The firmness was reported as peak force and expressed in newtons per gram of sample.

The industrial assay was carried out in the producer's field (Huelva, Spain) with $800 \mathrm{~kg}$ of fresh strawberries using the selected coating (carrageenan + calcium-see Section 3). The coating was sprayed (with a $10 \mathrm{~L}$ shoulder strap pressure sprayer) in every $5 \mathrm{~kg}$ perforated tray in the assembled $800 \mathrm{~kg}$ pallet, and then allowed to drip. The pallet of strawberries was stored in a controlled temperature chamber $\left(0-5^{\circ} \mathrm{C}\right)$ with a relative humidity of $85-90 \%$ and ventilation to reduce the overall temperature of the fruit. The coated and uncoated fruit were taken through the normal chain of transportation from the producer to the processing plant (approximately 2 days).

For the industrial assays, the firmness was reported in terms of internal and external firmness as determined by an Instron 3342 machine (USA) with a perforation needle ( $3 \mathrm{~mm}$ of diameter) using a $500 \mathrm{~N}$ compression load cell. Perforations of $3 \mathrm{~mm}$ depth were made in each assay at a velocity of $30 \mathrm{~mm} / \mathrm{min}$. For each firmness determination 20 strawberries were randomly chosen and, for each strawberry, the firm- ness was determined at four different points (both internal and external). The firmness is reported in terms of maximum load $(\mathrm{kN})$.

\subsection{Microbial assays}

The total microbial count was made according to the Portuguese standard NP 4405 (2002). The samples were collected in sterilized jars and homogenized in aseptic conditions. One milliliter of each sample was transferred to each of two Petri dishes. To each inoculated dish, approximately $15 \mathrm{~mL}$ of Plate Count Agar was added and cooled to $44-47^{\circ} \mathrm{C}$. The samples were mixed immediately after pouring by rotating the Petri dish sufficiently to obtain evenly dispersed colonies after incubation. After complete solidification, the plates were inverted and incubated at $30 \pm 1{ }^{\circ} \mathrm{C}$ for $72 \pm 3 \mathrm{~h}$. The count was expressed in $\mathrm{CFU} / \mathrm{g}_{\text {sample }}$.

\subsection{Statistical analysis}

SPSS software (Version 12.0, SPSS Inc., US) was used for all statistical analysis. Analysis of variance (ANOVA), $T$-test and regression analysis were applied at a significance level of 0.05 . Values followed by the same letter are not significantly different.

\section{Results and discussion}

\subsection{Critical surface tension}

According to Zisman (1964), in systems having a surface tension lower than $100 \mathrm{mN} / \mathrm{m}$ (low-energy surfaces), the contact angle formed by a drop of liquid on the solid surface will be a linear function of the surface tension of the liquid, $\gamma_{\mathrm{LV}}$ (were phase $\mathrm{V}$ is air saturated with the vapor of liquid, L). According to Owens and Wendt (1969), Rabel (1971) and Kaelble (1970) the surface tension of the liquid can be separated according to the interactions between their molecules. Such interactions are of two types: polar and dispersive. Given a pure liquid, for which the surface tension and its polar $\left(\gamma_{\mathrm{L}}^{\mathrm{p}}\right)$ and dispersive $\left(\gamma_{\mathrm{L}}^{\mathrm{d}}\right)$ contributions are known, if $\theta$ is the contact angle between the liquid and some solid, the interaction can be described in terms of the reversible work of adhesion, $W_{\mathrm{a}}$, as:

$$
\begin{aligned}
W_{\mathrm{a}} & =W_{\mathrm{a}}^{\mathrm{d}}+W_{\mathrm{a}}^{\mathrm{p}}=2\left(\sqrt{\gamma_{\mathrm{S}}^{\mathrm{d}}+\gamma_{\mathrm{L}}^{\mathrm{d}}}+\sqrt{\gamma_{\mathrm{S}}^{\mathrm{p}}+\gamma_{\mathrm{L}}^{\mathrm{p}}}\right) \\
& =\gamma_{\mathrm{L}}(1+\cos \theta)
\end{aligned}
$$

where $\gamma_{\mathrm{S}}^{\mathrm{p}}$ and $\gamma_{\mathrm{S}}^{\mathrm{d}}$ are the polar and dispersive contributions of the surface of the studied solid. Rearranging Eq. (1), yields:

$$
\frac{1+\cos \theta}{2} \frac{\gamma_{\mathrm{L}}}{\sqrt{\gamma_{\mathrm{L}}^{\mathrm{d}}}}=\sqrt{\gamma_{\mathrm{S}}^{\mathrm{p}}} \sqrt{\frac{\gamma_{\mathrm{L}}^{\mathrm{p}}}{\gamma_{\mathrm{L}}^{\mathrm{d}}}}+\sqrt{\gamma_{\mathrm{S}}^{\mathrm{d}}}
$$


Table 1

Surface tension components of the liquids used for characterization of the strawberry surface

\begin{tabular}{lllc}
\hline Compound & $\gamma_{\mathrm{L}}(\mathrm{mN} / \mathrm{m})$ & $\gamma_{\mathrm{L}}^{\mathrm{d}}(\mathrm{mN} / \mathrm{m})$ & $\gamma_{\mathrm{L}}^{\mathrm{p}}(\mathrm{mN} / \mathrm{m})$ \\
\hline Water $^{\mathrm{a}}$ & 72.10 & 19.90 & 52.20 \\
Bromonaphthalene $^{\mathrm{a}}$ & 44.40 & 44.40 & 0.00 \\
Formamide $^{\mathrm{a}}$ & 56.90 & 23.50 & 33.40 \\
Toluene $^{\mathrm{b}}$ & 28.50 & 27.18 & 1.32 \\
\hline
\end{tabular}

${ }^{\text {a }}$ Data adopted from Busscher et al., 1984.

b data adopted from Janczuk and Bialopiotrowicz, 1989.

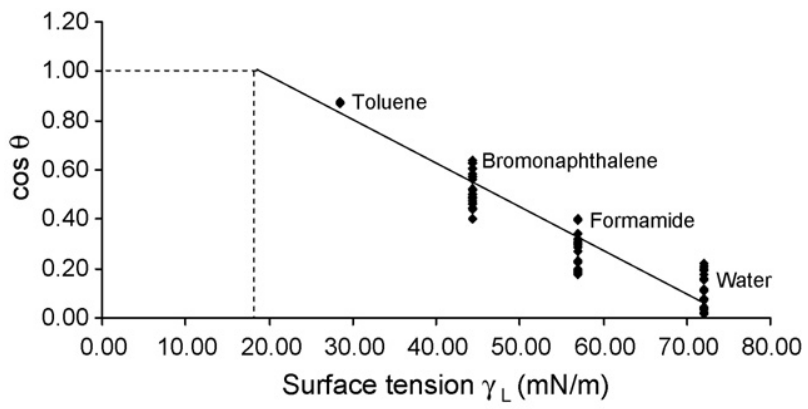

Fig. 1. Linear regression (confidence level of 0.05 and $n=80$ ).

Once experimental data are plotted in a graph of $1+$ $\cos \theta / 2 \gamma_{\mathrm{L}} / \sqrt{\gamma_{\mathrm{L}}^{\mathrm{d}}}$ versus $\sqrt{\gamma_{\mathrm{L}}^{\mathrm{p}} / \gamma_{\mathrm{L}}^{\mathrm{d}}}$, it is possible to obtain the values $\gamma_{\mathrm{S}}^{\mathrm{p}}$ and $\gamma_{\mathrm{S}}^{\mathrm{d}}$. It is also possible to define the cohesion coefficient $\left(W_{\mathrm{c}}\right)$, or work of cohesion, by:

$W_{\mathrm{c}}=2 \gamma_{\mathrm{LV}}$

This is related to the reversible work required to separate two surfaces of unit area of a material with a determined $\gamma_{S}$. While the adhesion forces cause the liquid to spread on the surface, the cohesion forces cause the liquid to contract. The balance between $W_{\mathrm{c}}$ and $W_{\mathrm{a}}$ gives the spreading coefficient, $W_{\text {s }}$, according to:

$W_{\mathrm{s}}=W_{\mathrm{a}}-W_{\mathrm{c}}$

The spreading coefficient, or wettability, represents the ability of a given liquid to spread on a solid surface. The maximum value that can be obtained for this coefficient is zero.

The surface tension determined for the strawberry was $28.94 \mathrm{mN} / \mathrm{m}$ (therefore, it is a low-energy surface), its polar and dispersive components being 5.95 and $22.99 \mathrm{mN} / \mathrm{m}$, respectively. These values, based on the data from Table 1 ,

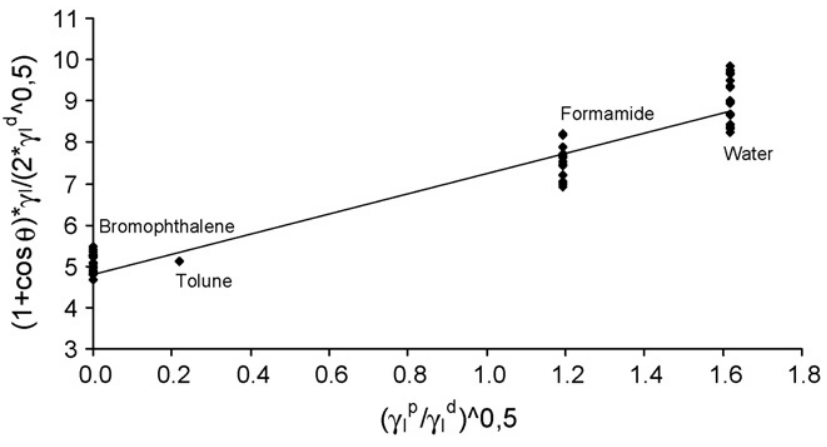

Fig. 3. Zisman plot for strawberry surface (confidence level of 0.05 and $n=80)$.

are reported in Fig. 1 according to Eq. (5).

$$
\begin{aligned}
\frac{1+\cos \theta}{2} \frac{\gamma_{\mathrm{L}}}{\sqrt{\gamma_{\mathrm{L}}^{\mathrm{d}}}}= & (2.1391 \pm 0.1229) \sqrt{\frac{\gamma_{\mathrm{L}}^{\mathrm{p}}}{\gamma_{\mathrm{L}}^{\mathrm{d}}}} \\
& +(4.7944 \pm 0.0093) ; \quad R=0.9712
\end{aligned}
$$

The correlation value $(R=0.9712)$ suggests a strong linear correlation between the dependent and independent variables. The validity of the global model was tested by the $F$-test, and the significance of the parameters of Eq. (5) was tested by the $T$-test, both with a significance level of 0.05 .

Since the surface of the strawberry is a low energy surface, it is now possible to apply the Zisman plot. According to Johnson and Dettre (1993) this kind of surface interacts with liquids primarily by dispersion forces. This fact explains why drops of polar liquids were not absorbed after a short period (Figs. 2 and 3). Again, the validity of the global model was tested by the $F$-test, while the significance of the parameters of Eq. (6) was tested by the $T$-test, both with a significance level of 0.05 .

Eq. (6) represents the linear regression to the data in Fig. 3.

$\cos \theta=(-0.0175 \pm 0.0008) \gamma_{\mathrm{L}}+(1.3339 \pm 0.0011) ;$

$R=0.9683$

The determination coefficient $\left(R^{2}=0.94\right)$ indicates that there is a strong linear association between the cosine of the contact angle $(\theta)$ and the surface tension of the tested liquid, $94 \%$ of the variation of $\cos \theta$ being explained by the model. In spite of the good correlation, the values obtained should

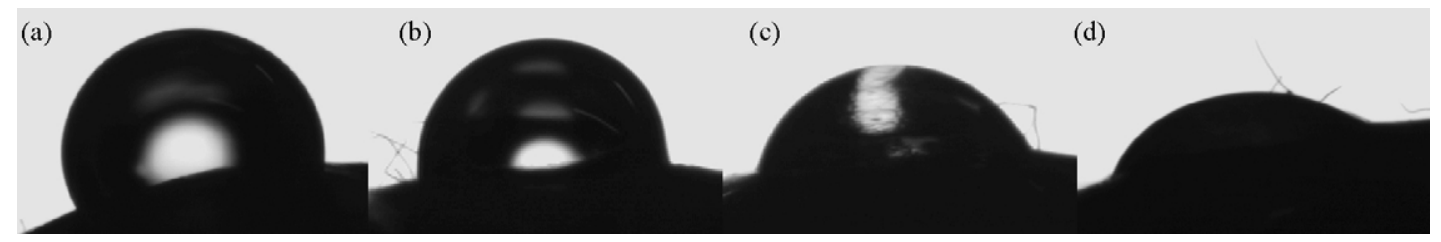

Fig. 2. Contact angle of the tested liquids on strawberry surface: (a) water; (b) formamide; (c) bromonaphthalene; (d) toluene. 
Table 2

Critical surface tension of fruit and vegetables

\begin{tabular}{lll}
\hline Vegetable/fruit & $\begin{array}{l}\text { Critical surface } \\
\text { tension }(\mathrm{mN} / \mathrm{m})\end{array}$ & Temperature $\left({ }^{\circ} \mathrm{C}\right)$ \\
\hline Strawberry $^{\mathrm{a}}$ & 18.8 & 19 \\
Apple $^{\mathrm{b}}$ & 18.7 & 26 \\
Garlic $^{\mathrm{c}}$ & 18.3 & 23 \\
Orange $^{\mathrm{d}}$ & 23.0 & 25 \\
Grapefruit $^{\mathrm{d}}$ & 23.0 & 25 \\
\hline${ }^{\text {a }}$ Present work. & \\
${ }^{\mathrm{b}}$ Choi et al., 2002. & \\
${ }^{\mathrm{c}}$ Hershko and Nussinovitch, 1998. \\
d Hagenmaier and Baker, 1993.
\end{tabular}

be analyzed with precaution, because the strawberry surface is very irregular and for rough surfaces the spreading is optimized for liquids with a contact angle below $90^{\circ}$ (Oliver and Mason, 1977) and inhibited for values above $90^{\circ}$ (Hershko and Nussinovitch, 1998).

The characterization of the surface of some vegetables and fruit has been made by Hagenmaier and Baker (1993), Hershko and Nussinovitch (1998) and Choi et al. (2002), among others, and Table 2 summarizes their results in terms of the critical surface tension $\left(\gamma_{\mathrm{C}}\right)$.

The critical surface-tension values have been reported to be lower than the surface tension values of the corresponding tested surfaces (Dann, 1970). The present study confirms this, the critical surface tension having a value of $18.84 \mathrm{mN} / \mathrm{m}$ (from Eq. (6)) and the strawberry surface tension having a higher value, $28.94 \mathrm{mN} / \mathrm{m}$ (from Eq. (4)).

\subsection{Wettability of the coating solutions}

The optimization of the composition of the coating solutions can be made by considering three parameters: the wettability, the adhesion coefficient and the cohesion coefficient. The control of the adhesion and cohesion coefficients is very important because the former promotes the spreading of the liquid while the later promotes its contraction.

The best results for the starch coating were obtained with the addition of $2 \%$ sorbitol. This is very interesting because Garcia et al. (2001), studying the gas permeabilities of starchbased edible coatings, found that solutions with sorbitol as a plasticizer presented lower permeabilities to water vapor, $\mathrm{O}_{2}$

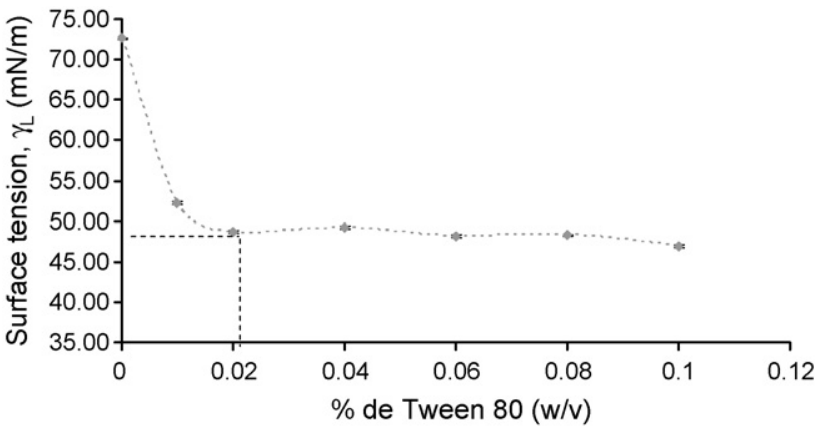

Fig. 4. Variation of surface tension of the carrageenan based coating with the addition of Tween 80 (average \pm confidence interval, $\alpha=0.05$ and $n=20$ ).

and $\mathrm{CO}_{2}$, characteristics which are desirable for the modification of the internal atmosphere of the fruit.

The high surface tension of carrageenan coatings (see Table 3) indicates that the forces between molecules of the coating are very strong, leading to high contact angles on the strawberry surface. To minimize this problem, Tween 80 was added and led to a significant reduction of $\gamma_{\mathrm{L}}$, as seen in Fig. 4. It was interesting to find that from a certain (critical) concentration of Tween $80(0.02 \%)$ onwards, $\gamma_{\mathrm{L}}$ was practically constant.

Choi et al. (2002) reported that the addition of $1 \%$ Tween 80 to a solution of $1.5 \%$ chitosan increased the compatibility between the coating and the skin of apples, reducing the superficial tension of the liquid and thus increasing the spreading coefficient. The addition of Tween 80 is also in conformity with the work of El Ghaouth et al. (1991) and Zhang and Quantick (1997) that suggested $0.1 \%$ Tween 80 for $1 \%$ chitosan solutions. In accordance with the quoted work, the same value of Tween 80 concentration was used in the present study, the surface tension of the coating thus obtained being similar to the one reported by Choi et al. (2002).

\subsection{Oxygen permeability}

As mentioned before the modification of the internal atmosphere may cause disorders associated with high $\mathrm{CO}_{2}$ and/or low $\mathrm{O}_{2}$ concentration. As shown in Table 4, starch films were approximately three times thicker than the carrageenan films; these data are explained by the higher surface tension

Table 3

Surface tension $\left(\gamma_{\mathrm{L}}\right)$, interfacial tension solid-liquid $\left(\gamma_{\mathrm{SL}}\right)$, contact angle $(\theta)$, wettability, adhesion and cohesion coefficients obtained for the different coatings (average \pm confidence interval, $\alpha=0.05$ and $n=20$ )

\begin{tabular}{llll}
\hline & Edible coating & & \\
\cline { 2 - 4 } & Starch & Carrageenan & Chitosan \\
\hline Plasticizer & $2.0 \%$ sorbitol & $0.75 \%$ glycerol $+0.02 \%$ Tween 80 & $0.10 \%$ Tween 80 \\
$\theta\left({ }^{\circ}\right)$ & $83.03 \pm 3.46$ & $86.07 \pm 1.03$ & $80.01 \pm 3.51$ \\
$\gamma_{\mathrm{L}}(\mathrm{mN} / \mathrm{m})$ & $50.71 \pm 0.27$ & $48.62 \pm 0.18$ & $46.98 \pm 0.07$ \\
$\gamma_{\mathrm{SL}}(\mathrm{mN} / \mathrm{m})$ & $22.83 \pm 3.05$ & $25.60 \pm 0.88$ & $20.85 \pm 2.83$ \\
$W_{\mathrm{S}}(\mathrm{mN} / \mathrm{m})$ & $-44.61 \pm 3.05$ & $-45.28 \pm 0.88$ & $-38.89 \pm 2.83$ \\
$W_{\mathrm{a}}(\mathrm{mN} / \mathrm{m})$ & $56.82 \pm 3.04$ & $51.96 \pm 0.92$ & $55.06 \pm 2.84$ \\
$W_{\mathrm{c}}(\mathrm{mN} / \mathrm{m})$ & $101.43 \pm 0.54$ & $97.24 \pm 0.36$ & $93.95 \pm 0.14$ \\
\hline
\end{tabular}


Table 4

Thickness and permeability to oxygen of starch and carrageenan films (average \pm confidence interval, $\alpha=0.05$ )

\begin{tabular}{|c|c|c|c|}
\hline Edible coating & & Thickness, $x 10^{4}(\mathrm{~m})$ & $\begin{array}{l}\text { Permeability } \mathrm{O}_{2}, \mathrm{P}_{\mathrm{O}_{2}} 10^{12} \\
\left(\mathrm{~cm}^{3} \mathrm{~m} \mathrm{~m}^{-2} \mathrm{~Pa}^{-1} \mathrm{~s}^{-1}\right)\end{array}$ \\
\hline Starch & $\begin{array}{l}\text { Without calcium } \\
\text { With calcium }\end{array}$ & $\begin{array}{l}1.2 \pm 0.1 \mathrm{a} \\
1.4 \pm 0.0 \mathrm{~b}\end{array}$ & $\begin{array}{l}13.19 \pm 6.97 \mathrm{a} \\
10.41 \pm 2.14 \mathrm{a}\end{array}$ \\
\hline Carrageenan & $\begin{array}{l}\text { Without calcium } \\
\text { With calcium }\end{array}$ & $\begin{array}{l}0.4 \pm 0.0 \mathrm{c} \\
0.4 \pm 0.0 \mathrm{c}\end{array}$ & $\begin{array}{l}4.19 \pm 0.66 b \\
4.44 \pm 0.13 b\end{array}$ \\
\hline
\end{tabular}

of the starch solution. In fact, this means that the cohesion coefficient is higher for the starch solution than it is for the carrageenan solution, which in practice results in stronger attractive forces between the polymer molecules in the former case than in the latter. However, even though the starch films are thicker, they are more permeable to $\mathrm{O}_{2}(T$-test with a significance level of 0.05), a fact which can be associated with the high concentration of plasticizers. In fact, plasticizers are used to decrease the intermolecular attractions between adjacent polymeric chains (Kester and Fennema, 1986), which in turn facilitates the penetration of gas molecules through that network.

\subsection{Postharvest application}

\subsubsection{Laboratory scale}

This part of the work aimed at determining which coating was more efficient in retarding strawberry senescence. Loss of texture is dependent on both cell wall degradation and loss of turgidity of the tissue. The strawberries coated with carrageenan, chitosan and chitosan and calcium presented the smallest loss of firmness (Fig. 5). These results are in agreement with those obtained by Garcia et al. (1996), who reported that the presence of calcium in postharvest treatments delayed the loss of firmness of fresh strawberries. Calcium chloride addition seems to influence the firmness

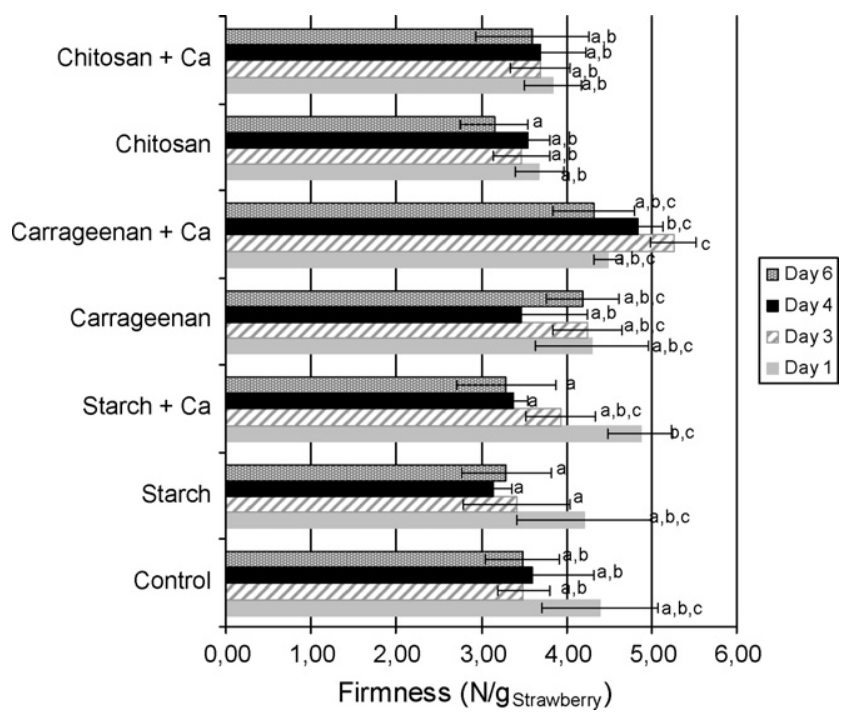

Fig. 5. Firmness changes in the strawberry fruit with and without coating during storage (average \pm standard deviation, $n=4$ ).

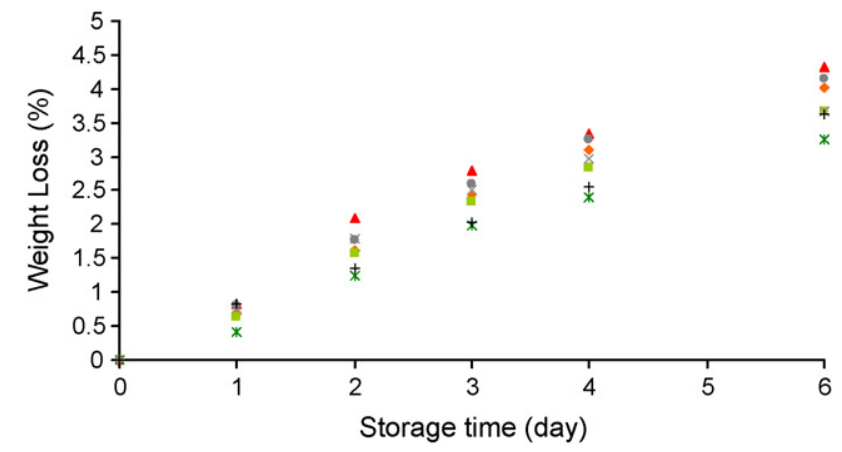

Fig. 6. Strawberry weight loss: uncoated $(O)$, starch coating $(\square)$, starch and calcium chloride coating $(\mathbf{\Lambda})$, carrageenan coating $(\times)$, carrageenan and calcium chloride coating $(X)$, chitosan coating $(*)$, chitosan and calcium chloride coating $(+)$, during storage (average \pm standard deviation, $n=3$ ).

of the fruit, although this cannot be statistically determined when looking just at the average values and their respective standard deviations.

The smallest loss of weight was obtained with chitosan and carrageenan coatings, both with calcium chloride (Fig. 6), there being no significant differences between them. The water vapor transference, mainly responsible for this loss of weight, occurs generally through the hydrophilic part of the film, thus the permeability to water vapor depends on the ratio of the hydrophilic/hydrophobic components (Hernandez, 1994). Even though polysaccharide films have high selectivity to $\mathrm{O}_{2}$ and $\mathrm{CO}_{2}$, they are very permeable to water vapor; this fact explains why there were not large differences between coated and uncoated fruit. To avoid this, addition of lipids to the coatings should be considered.

The soluble solids percentage did not vary significantly during storage (with values between $7.2 \%$ and $8.2 \%$ ). The strawberries coated with chitosan and calcium chloride coating presented the smaller variation in the soluble solids content, although the differences between coated and uncoated fruit were statistically not significant.

Color changes in fresh fruit are a good indication of maturation. In this work no significant changes were obtained for lightness ( $L^{*}$ values between 27.8 and 31.5). With the exception of the strawberries without coating, which had a considerable variation in the chromaticity coordinates, the coated fruit kept approximately the same values of $a^{*}$ and $b^{*}$ until the fourth day of storage, with chroma values varying between 37.5 and 41.0. At the sixth day of storage a decrease in the chromaticity coordinates was observed in the fruit 
coated with starch, carrageenan and calcium, and chitosan solution, a result mainly of the reduction of the coordinate $a^{*}$. Coordinate $b^{*}$ slightly diminished for all the studied fruit, indicating a loss of yellowness. This reduction is expressed as a typical dark red, very common in very mature fruit. The presence of calcium did not seem to influence the color of the fruit.

Garcia et al. (2001) reported constant chromaticity coordinates during a period of 8 days with coated strawberries. The difference in this work can be explained by the fact of the fruit used in the present study were bought in the local market, being exposed to more adverse conditions.

Despite the fact that overall appearance of the coated strawberries remained approximately the same as the uncoated control fruit, the carrageenan-coated fruit appeared to have a more glossy/shiny surface.

\subsection{Microbial assays}

The evaluation of the growth of microorganisms on the surface of the fruit can be made by the assessment of the respective growth rate, $\mu_{\mathrm{c}}$, determined as

$\frac{1}{q} \frac{\mathrm{d} q}{\mathrm{~d} t}=\mu_{\mathrm{c}}$

were $q$ is the population density (expressed as CFU/g strawberry), and $t$ is time.

Even though the method accounts for both fungi and bacteria, visual analysis of the plates indicated that most of microorganisms on strawberry were fungi. When assessing the microbial growth at the surface of the fruit, the comparison of growth rates for the coatings indicated that coatings with calcium chloride had lower values of $\mu_{\mathrm{c}}$ than the those without this salt (Fig. 7 and Table 5). Tissue maceration results in an adequate supply of nutrients for pathogen growth. Calcium has long been used as a firmness agent and therefore it may have an important role in the reduction of the growth rate by depriving the microbes of nutrients. The low-

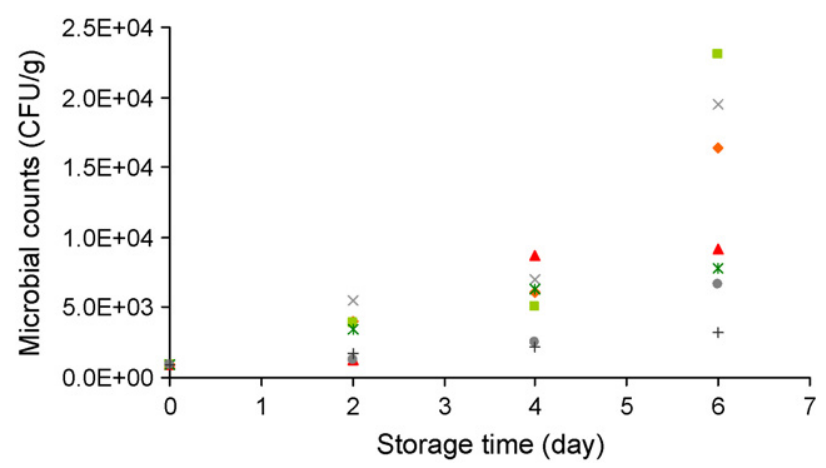

Fig. 7. Microbial growth in fresh strawberries: uncoated $(-)$, starch coating $(\square)$, starch and calcium chloride coating $(\mathbf{\Lambda})$, carrageenan coating $(\times)$, carrageenan and calcium chloride coating $(X)$, chitosan coating $(*)$, chitosan and calcium chloride coating (+), during storage (according to NP4405).
Table 5

Rate of microbial growth and correlation coefficient obtained for coated and uncoated strawberries stored at $0-5{ }^{\circ} \mathrm{C}$

\begin{tabular}{lll}
\hline Coating & $\begin{array}{l}\mu_{\mathrm{c}}(\mathrm{CFU} / \\
\left.\left(\mathrm{g}_{\text {strawberry }} \text { day }\right)\right)\end{array}$ & $\begin{array}{l}\text { Correlation } \\
\text { coefficient }(R)\end{array}$ \\
\hline Control & 0.462 & 0.975 \\
Starch & 0.506 & 0.971 \\
Starch $+\mathrm{CaCl}_{2}$ & 0.449 & 0.934 \\
Carrageenan & 0.480 & 0.953 \\
Carrageenan $+\mathrm{CaCl}_{2}$ & 0.360 & 0.939 \\
Chitosan & 0.339 & 0.985 \\
Chitosan $+\mathrm{CaCl}_{2}$ & 0.204 & 0.978 \\
\hline
\end{tabular}

est microbial growth rate occurred when chitosan coatings were used; this fact could be attributed to either its fungistatic properties or/and its ability to induce defense enzymes and phytoalexins in plants (Mauch et al., 1984; El Ghaouth et al., 1992).

\subsection{Industrial scale tests}

Based on the results described in the preceding sections the carrageenan and chitosan coatings with calcium were selected for industrial validation. That carrageenan is widely known as a food additive both in the US and Europe influenced its choice for industrial scale tests. The application of the coating was made immediately after harvest by spraying the fruit; the coated and uncoated fruit were taken through the normal chain of transportation from the producer to the processing plant. Once there, the texture was determined in terms of external and internal firmness, 2 and 5 days after harvest (Fig. 8).

No significant differences in internal firmness were obtained between the coated and uncoated fruit, even though the average value of firmness of uncoated fruit was lower after 2 and 5 days of shelf-life. However the same did not occur with the external firmness. In this case, the coated fruit presented a significantly higher value of external firmness than the uncoated ones during shelf-life. This seems to signify that the calcium does not penetrate deep into the tissue, rather acting on the surface of the fruit.

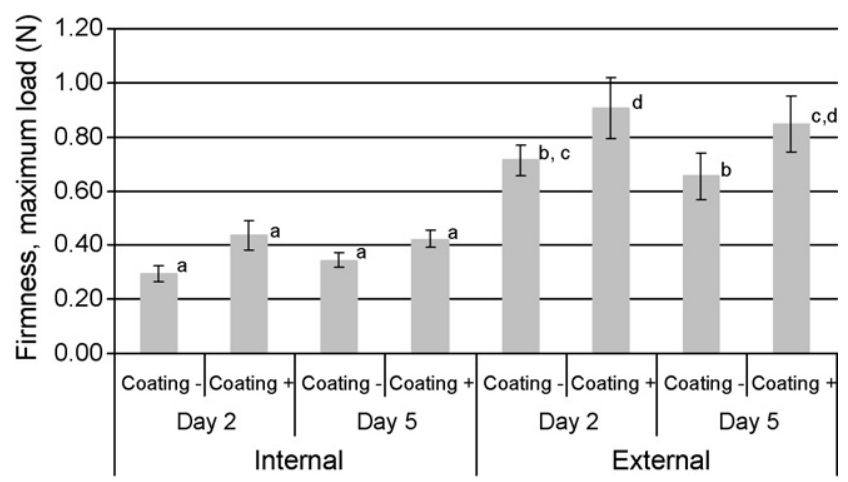

Fig. 8. Internal and external firmness of coated and uncoated strawberries (average \pm confidence interval, $\alpha=0.05$ and $n=20$ ). 


\section{Conclusions}

This study shows that the strawberry surface is a low energy surface with a surface tension of $28.94 \mathrm{mN} / \mathrm{m}$, and polar and dispersive components of 5.95 and $22.99 \mathrm{mN} / \mathrm{m}$, respectively. The critical surface tension of the strawberry surface is $18.84 \mathrm{mN} / \mathrm{m}$. Oxygen permeability of carrageenan films was significantly lower than that of starch films. This could explain the less interesting results obtained with starch coatings. Carrageenan films were also found to be less opaque than those made of starch. While it has been confirmed that the addition of calcium chloride to coatings decreases the microbial growth rate of the fruit, the minimum rate of microbial growth was obtained with strawberries coated with chitosan and calcium chloride. In terms of color, no significant differences were found between the chromaticity coordinates of the untreated fruit as compared with the treated fruit. The minimum loss of firmness was obtained in strawberries coated with carrageenan and calcium chloride. The minimum weight loss was obtained in fruit with chitosan and carrageenan coatings, both with calcium chloride, and no soluble solids differences were found. The industrial application of the carrageenan coating with calcium on fresh fruit improved the external firmness of the fresh strawberries.

\section{References}

ASTM D 3985-02. 2002. Standard test method for oxygen gas transmission rate through plastic film and sheeting using a coulometric sensor. In: ASTM Book of Standards 15.09.

Ben-Yehoshua, S., 1969. Gas exchange, transportation, and the commercial deterioration in storage of orange fruit. J. Am. Soc. Hort. Sci. 94, 524-528.

Busscher, H.J., Van Pelt, A.W., De Boer, P., De Jong, H.P., Arends, J., 1984. The effect of surface roughening of polymers on measured contact angles of liquids. Colloids Surf. 9, 319-331.

Choi, W., Park, H., Anh, D., Lee, J., Lee, C., 2002. Wettability of chitosan coating solution on "Fuji" apple skin. J. Food. Sci. 66, 26682672.

Dann, J.R., 1970. Forces involved in the adhesive process 1. Critical surface tensions of polymeric solids as determined with polar liquids. J. Colloid Interface Sci. 32, 302-319.

El Ghaouth, A., Arul, J., Ponnampalam, R., Boulet, M., 1991. Chitosan coating effect on storability and quality of fresh strawberries. J. Food Sci. 56, 1618-1620.

El Ghaouth, A., Arul, J., Asselin, A., Benhamon, N., 1992. Antifungal activity of chitosan on post-harvest pathogens: induction of morpho- logical and cytological variations on Rhizopus stolonifer. Mycol. Res. 96, 769-779.

Garcia, J., Herrera, S., Morilla, A., 1996. Effects of postharvest dips in calcium chloride on strawberry. J. Agric. Food Chem. 44, 30-33.

Garcia, M., Martino, M., Zaritzky, N., 2001. Composite starch-based coatings applied to strawberries (Fragaria ananassa). Food/Nahrung. 45, 267-272.

Hagenmaier, R.D., Baker, R.A., 1993. Reduction in gas exchange of citrus fruit by wax coatings. J. Agric. Food Chem. 41, 283-287.

Hernandez, E., 1994. Edible coatings for lipids and resins. In: Krochta, J., Baldwin, E., Nisperos-Carriedo, M. (Eds.), Edible Coatings and Films to Improve Food Quality. Technomic Publishing Company.

Hershko, V., Nussinovitch, A., 1998. The behaviour of hydrocolloid coatings on vegetative materials. Biotechnol. Progr. 14, 756-765.

Janczuk, B., Bialopiotrowicz, T., 1989. Surface free-energy components of liquids and low energy solids and contact angles. J. Colloid Interface Sci. 127, 189-204.

Johnson, R.E., Dettre, R.H., 1993. Wetting of low-energy surfaces. In: Berg, J.C. (Ed.), Wettability. Marcel Dekker Inc., New York, pp. 1-73.

Kaelble, D.H., 1970. Dispersion-polar surface tension properties of organic solids. J. Adhes. 2, 66-81.

Kester, J., Fennema, O., 1986. Edible films and coatings: a review. Food Technol. 40, 47-59.

Krochta, J., Mulder-Johnston, C., 1997. Edible and biodegradable polymer films challenges and opportunities. Food Technol. 51, 61-74.

Mauch, F., Hadwiger, L., Boller, T., 1984. Ethylene: symptom, not signal for the induction of chitinase and $\beta$-1,3-glucanase in pea pods by pathogens and elicitors. Plant Physiol. 76, 607-610.

Newman, A.W., Kwok, D.Y., 1999. Contact angle measurement and contact angle interpretation. Adv. Colloid Interface Sci. 81, 167-249.

Nisperos-Carriedo, M., 1994. Edible coatings and films based on polysaccharides. In: Krochta, J., Baldwin, E., Nisperos-Carriedo, M. (Eds.), Edible Coatings and Films to Improve Food Quality. Technomic Publishing Company.

NP 4405. 2002. Food Microbiology-General guidance for the enumeration of micro-organisms, colony count technique at $30^{\circ} \mathrm{C}$. Lisbon: IPQ.

Oliver, J.F., Mason, S.G., 1977. Microspreading studies of rough surface by scanning electron microscopy. J. Colloid Interface Sci. 60, 480-487.

Owens, D.K., Wendt, 1969. Estimation of the surface free energy of polymers. J. Appl. Polym. Sci. 13, 1741-1747.

Park, H., 1999. Development of advanced edible coatings for fruit. Trends Food Sci. Technol. 10, 254-260.

Rabel, W., 1971. Einige aspekte der benetzungstheorie und ihre anwendung auf die untersuchung und veränderung der oberflächeneigenschaften von polymeren. Farbe und Lack 77, 997-1006.

Song, B., Springer, J., 1996. Determination of interfacial tension from the profile of a pendant drop using computer-aided image processing. J. Colloid Interface Sci. 184, 64-91.

Zhang, D., Quantick, P., 1997. Effects of chitosan coating on enzymatic browning and decay during postharvest storage of litchi (Litchi chinensis Sonn) fruit. Postharvest Biol. Technol. 12, 195-202.

Zisman, W.A., 1964. Contact angle wettability and adhesion. In: Advances in Chemistry Series, 43. American Chemical Society. 